\title{
XXXVII. Extracts from a prize essay on iodine
}

\section{James Inglis M.D.}

To cite this article: James Inglis M.D. (1836) XXXVII. Extracts from a prize essay on iodine , Philosophical Magazine Series 3, 8:46, 191-192, DOI: 10.1080/14786443608648846

To link to this article: http://dx.doi.org/10.1080/14786443608648846

册 Published online: 01 Jun 2009.

Submit your article to this journal 준

Џ Article views: 2

Q View related articles $₫$ 
hand, it will retain some part of that heat for a minute or more; but in this experiment the heat vanishes in a moment. It is not, therefore, heated glass which we feel, but heat which has come through the glass, in a free or radiant state.

XXXVII. Extracts from a Prize Essay on Iodine. By $\mathrm{J}_{\mathrm{AMES}}$ INGLIS, M.D.

[Continued from p. 20, and concluded.]

I MENTIONED before that Serullas had proposed iodic acid as a test for the vegetable alkalies. I find that hydriodic acid may be used as such also. To the sulphate of quinine $I$ added in solution a few drops of sulphuric acid, so that the sulphate might be soluble in water. I next added a solution of hydriodate of potassa ; instantly there was a yellow precipitation, which became gradually of a greenish colour. I added more hydriodate, and the precipitation of yellow iodide of quinine still took place, which finally became of a reddish brown colour. I have not examined this compound, but call it iodide of quinine, the hydriodates being all soluble; and I do not see how it could be an iodate.

I find also that the hydriodate of potassa throws down a white precipitate with tincture of capsicum. I cannot decidedly say that this acid is as good a general test as the iodic. * * * *

I wished to obtain a compound of cyanogen with iodine, and for this purpose made a solution of bicyanuret of mercury in water, which I added to an alcoholic solution of iodine; immediately the red biniodide of mercury fell, and the action I thought to be this :

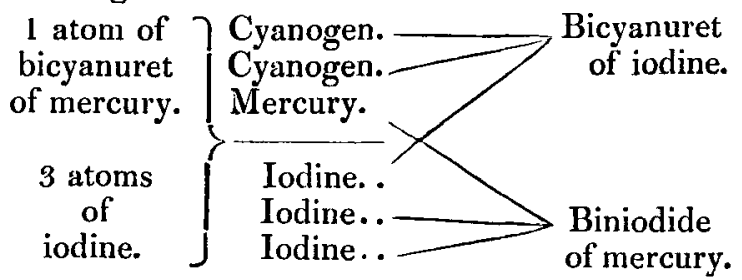

If too much cyanuret of mercury be added, then all the precipitation is red. But if there be only sufficient, then a lightish brown powder in crystals falls. I boiled and strained off the supernatant liquor from the biniodide of mercury, and laid it aside to crystallize; but this could not be effected. The liquid is exceedingly pungent, and exhales a vapour 
painful to the eyes. When added to water a copious yellow precipitation takes place. It contains about two thirds of alcohol; is, when pure, of a clear amber colour; when placed on the skin it causes a painful sensation, and excites an inflammatory blush. It, after being boiled, deposits acicular red crystals, interspersed with yellow ones of a similar shape. Even when much diluted with either water or alcohol, the odour and taste of this new cyanide are very pungent. * * *

I next wished to obtain an iodide of chromium, and this I endeavoured to do in the same manner as the chloride is got. I mixed a drachm of the hydriodate of potassa with half a drachm of the bichromate of potassa, and adding fuming sulphuric acid, I distilled; but could not succeed in procuring it. In the Lond. and Edinb. Phil. Mag. and Journal of Science, (No. 15. September, 1833, vol. iii. p. 235,) $I$ observed that $M$. Peligot describes a compound of chromic acid with metallic chlorides. I thought that some analogous compound might be formed with the metallic iodides.

To the bichromate of potassa in solution, and when boiling, I added concentrated hydriodic acid in excess. A considerable portion of iodine is evolved, and a thick black compound formed, having iodine in excess. I put a portion of this into water, and having boiled it, laid it aside to cool. No crystallization took place, but the solution was of a decided green colour.

The black compound when dried and broken into pieces resembles kino; it is of a dark green colour, with considerable lustre, and is friable. The liquid that drained from it gave crystals of hydriodate of potash. The action I suppose to be as follows :

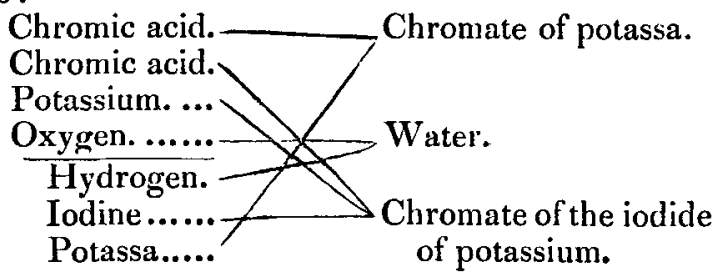

I thought that hydrocyanic acid, being of easy decomposition, would, when combined with tincture of iodine, give hydriodic acid and a cyanuret of iodine. I allowed them to react on each other for some weeks; no deposition was observed, but on testing the fluid, hydriodic acid is readily detected. I consider this solution as a hydriodate of the iodide of cyanogen." * * * * * 